\title{
Parental Involvement in Children's School Readiness: Parents' Perceptions, Expectations and Practices in America
}

\author{
Xiaoying Xia \\ School of Education, Shanghai Normal University Tianhua College, Shanghai 20185, China; \\ xxy198@aliyun.com
}

Keywords: Parental involvement, School readiness, Perception, Expectation, Practice.

\begin{abstract}
The purpose of this study is to gain an understanding of parents' perceptions, expectations, and practices in preschool children's school readiness for kindergarten in America. Two mothers who came from a school district in Northern California, U.S. were recruited to participate in this qualitative study. This study found that parents tend to associate school readiness with academic, social, cognitive skills but generally ignore the physical development domain. Parents showed great concerns for children's social transition to the kindergarten and valued free-play experience for young children in the preschool and perceived it as an important way to foster children's social abilities. Parental involvement practices include a wide array of transitional practices at home, school, and in the community but effective practices need to be tailored to children's personalities and development status. Implications for educators, school administrators, and parents of preschoolers are discussed.
\end{abstract}

\section{Introduction}

Research show that parental involvement has positive effects on children's academic achievement and social-emotional wellbeing (Englund, Luckner, Whaley, \& Egeland, 2004). Parents' decisions to be involved in children's education are largely influenced by their beliefs and values about school readiness (Graue, 1992). Parents who put higher value on academic skills are more likely to provide literacy-rich home environment and intentionally teach their children these skills. In fact, what parents consider as important is positively associated with how their children's skills develop (Barbarin et al., 2008). Apart from parents' beliefs, the expectation parents have for their children is another important factor to consider. Parents' high expectations for future educational attainment are related to children's current school grades and their long-term educational attainment (Froiland, Peterson, \& Davison, 2013). Asian American children's higher achievement levels were found to be strongly correlated with their parents' higher educational expectations (Goyette \& Xie, 1999). The positive impact of parents' involvement practices, beliefs, and expectations on children's school readiness have been well documented with quantitative research methodology in the literature. Nevertheless, children's development is shaped by the complicated interplay of families, schools and communities. This study attempts to adopt a qualitative research method to explore the authentic experiences of parents in preparing their children to enter kindergarten. Three research questions are designed to guide the study: 1) What are parents' perceptions about readiness for kindergarten? 2) What are parents' expectations for children's school readiness skills and preparation? 3) What are the practices that parents adopt to prepare their children for kindergarten?

\section{Methodology}

This study employed a naturalistic qualitative approach to explore parents' experiences in their children's transition to kindergarten. Purposeful sampling strategies were used to locate information-rich respondents. The two respondents of this study come from a school district in Northern California, U.S. Both of them are mothers of two children. The first mother(Amy) is a preschool teacher who had a daughter attending Pre-K 2 and another daughter already in Grade 1 . The second one (Mary) is a stay-at-home mother who had two children, one is attending Pre-K 2 and 
another child still at kindergarten. Both of the two respondents are undergoing the school transition of one child and have experienced this phenomenon for another one. I conducted one-on-one interviews with two parents with a interview protocol. The transcription had all been presented for the respondents' review and correction. Apart from the respondents' interviews, I observed the class of the children whose parents participated in the study and took down notes on how the two children behaved and interacted with other children in class. I also talked to the teachers about the performance of the respondents' children and reviewed children's coursework and portfolios.

\section{Research Findings}

\subsection{Perceptions of School Readiness}

When asked about parents' understanding about school readiness, both of the two respondents were likely to cite specific skills as indicators of readiness. Words like "socially ready" and "academically ready" have been mentioned most frequently. They emphasized the importance of specific skills such as letter recognition, sound/letter association, and the ability to write one's own name as well as pre-reading skills. On the part of social-emotional skills, they mentioned skills such as following directions, interacting with peers, communicating needs, and taking turns as critical for children's school readiness. Compared with academic skills, both parents attached more importance to children's social-emotional maturity. They believed that a good acquisition of social skills as essential for being ready for kindergarten. One mother said, "Academic skills or social skills, if I have to pick, I would probably say social-emotional. If she is social-emotionally ready, then everything else is so cut." According to her responses, if children display strong social-emotional competence, they will progress well in other developmental domains of school readiness.

\subsection{Importance of Attending Preschools}

Both of the two respondents underscored value of attending preschool program. They believed that quality preschool programs provide a solid foundation for their children's academic and social-emotional development. While I was observing the class, I noticed that Amy's daughter performed actively in the circle time. When teachers-initiated questions, the girl raised up her hands and bravely answered the teacher's question. Another respondent also mentioned the transition practices preschool normally provided for preparing children for kindergarten. In my class observation, I noticed that the teacher reiterated words like "This is required in the kindergarten". Preschool teachers related the expectations of kindergarten to children. In this way, children gradually gain familiarity with kindergarten and ease their tension of entering new schools. In parents' conversations, another recurring topic is the children's free-play experience in preschool. As one mother commented, "In preschool, play is very important and a way that they [children] learn how to understand various everyday life skills.”.

\subsection{Expectations for Children in Kindergarten}

In talking about the expectations, both of the two mothers put emphasis on social skills, independence and responsibility. One mother commented, "I expect that they [children] will become more independent....to respect us, their teachers and peers.” Similar to the preceding quotation, another mother expected her children to be nice to other and be independent. Both of the two respondents expected their children to display good conducts in kindergarten and handle things independently. One of the mothers also ex-pressed concerns about following the school routines. "Nap time is our biggest challenge. She got nap time at preschools while going to kindergarten they have no nap time. That's our hardest transition.” From their responses, we can see that parents show greatest concerns about children's social adjustment in the new environment.

\subsection{Transitional Practices}

The two interviewees talked about the transitional practices they adopt at home, school and community. At home, they all endorsed the play-based transitional practices in educating their children such as flashcards, games, etc. In the community, they exposed children to a range of experiences such as taking children to zoos, museums. They also did some activities to arouse children's enthusiasm about going to new schools, like buying them new schoolbags and talking 
positively about the upcoming new schools. These practices can help children feel comfortable with the coming kindergarten. In addition to the active involvement in children's school readiness, respondents in this study also discussed about their supporting role as a parent for school. One of the participants commented, "Talking to the teacher, and finding out what they say they [children] need help with, just basically supporting at home”. Besides, role modelling was described as a good practice to teach children readiness skills, as a mother stated, "You have to take the initiative at home. And much learning comes from modeling. I believe kids learn from examples".

\subsection{Influence of Children's Characteristics on Parents' Beliefs}

A noteworthy finding of this study is that parents' beliefs about school readiness are influenced by their children's individual characteristics. When asked about what skills are more important for kindergarten, one of the mother shared her experiences with her two children, "Both of my kids are different. My oldest need more social-emotional skills but academics come perfectly fine. My youngest is socially and emotionally perfect. But academics is something I am worried about.” In terms of the transitional practices they adopt for children's transition, parents also put emphasis on children's personalities. They believed that parents need to tailor their involvement strategies to children's characteristics as different children required different parental involvement strategies. One of the parent commented, "What works for one child might not work for the other one."

\section{Discussion}

Parents tend to conceptualize school readiness as a series of academic and social skills. They rated basic knowledge of recognizing letters, numbers, shapes as important to be ready for school. In addition, they cited social skills such as taking turns, following directions, sharing, and getting along with other children as criteria for school readiness. Compared with academic abilities, parents regarded social skills as more important for children to perform successfully in kindergarten. Interestingly, although school readiness entails five domains of children's development, parents did not mention physical development and wellbeing.

As for the expectation for children in kindergarten, parents expected their children to adjust socially to the school environment, display good conducts, be independent and responsible. However, the contemporary early childhood educators tend to give intense attention to children's early literacy and cognitive development (McClelland et al., 2007). Preschools need to give priority to the cultivation of social skills in their childcare programs to meet the goals of parents. In parents' expectations, "play" is another recurring theme. They valued free-play experience for young children in the preschool and perceived it as an important way to foster children's social abilities. However, the growing demands for academic knowledge in kindergarten (Goldstein, 2007) have shifted the primary focus of preschool education from experiential, play-based programs to a more academic model (Hatcher, Nuner, Paulsel, 2012). Preschool and kindergarten educators need to be aware of parents' expectations for play-based learning experience.

The parents were actively involved in a wide array of transitional practices at home, school, and in the community. In addition, parents emphasized their supporting role for school by communicating with teachers about children's progress as well as problems. Parents can support their children's schooling by responding to school obligations and talking to their child's preschool teacher to find out what they should do at home to help prepare their children for entering kindergarten (Lahaie, 2008). Another effective practice parents adopt is scheduled routine. Family routines, like bedtime, waking time and activities, and dinnertime can help promote children's behavioral and academic competencies (Wildenger, McIntyre, Fiese, \& Eckert, 2008). Preschool practitioners should help families familiar with the regular mealtimes and bedtimes of transitioning kindergartners and carry out a similar schedule prior to school entry.

Parents' beliefs on school readiness and transitional practices are largely influenced by children's characteristics and development status. If children demonstrate deficient preparedness in emotion regulation, parents show more concern about training children to control their emotions in daily life and tend to cite regulating emotions as an important indicator for school readiness. However, many 
current studies used surveys to draw conclusions about parents' conceptions of school readiness (Diamond et al, 2000; Kim, Murdock \& Choi, 2005). They attributed the variance of parents' beliefs about kindergarten readiness to demographic characteristics such as age, education, income, and ethnic background but fail to take into account children's characteristics such as temperament, disposition, and developmental maturation. Future research need to consider children's individual differences when examining parents' perceptions and practices in children's school readiness.

\section{Conclusion}

This study explored parent's experiences and perceptions of preparing children for school based on inter-views with two Caucasian mothers in the U.S. both of whom have a child ready to enter kindergarten. It is a only a small-scaled qualitative study and the findings cannot be generalized to other parents. Future research can recruit larger numbers of parents with varying socio-economic status and ethnic backgrounds. In addition, the present study only examined the perspectives and experiences of mothers. Further studies can investigate father's perceptions and practices with regard to their children's school readiness and examine whether masculine gender can influence their beliefs. Also, the results of the current study raise questions on the role of children's characteristics in parents' perceptions of school readiness. Quantitative research can examine further the relationship between children's characteristics and parents' beliefs in school readiness.

\section{References}

[1]. Barbarin, O. A., Early, D., Clifford, R., Bryant, D., Frome, P., Burchinal, M., \& Pianta, R. (2008). Parental conceptions of school readiness: Relation to ethnicity, socioeconomic status, and children's skills. Early Education and Development, 19(5), 671-701.

[2]. Diamond, K. E., Reagan, A. J., \& Bandyk, J. E. (2000). Parents' conceptions of kindergarten readiness: Relationships with race, ethnicity, and development. The Journal of Educational Research, 94(2), 93-100.

[3]. Englund, M. M., Luckner, A. E., Whaley, G.J. L. \& Egeland, B. (2004). Children’s Achievement in Early Elementary School: Longitudinal Effects of Parental Involvement, Expectations, and Quality of Assistance. Journal of Educational Psychology, 96(4), 723-730.

[4]. Froiland, J. M., Peterson, A., \& Davison, M. L. (2013). The long-term effects of early parent involvement and parent expectation in the USA. School Psychology International, 34(1), 33-50.

[5]. Graue, M. E. (1992). Social interpretations of readiness for kindergarten. Early Childhood Research Quarterly, 7(2), 225-243.

[6]. Goyette, K., \& Xie, Y. (1999). Educational expectations of Asian American youths: Determinants and ethnic differences. Sociology of Education, 72 (1), 22-36.

[7]. Goldstein, L. S. (2007). Embracing pedagogical multiplicity: Examining two teachers' instructional responses to the changing expectations for kindergarten in US public schools. Journal of Research in Childhood Education, 21(4), 378-399.

[8]. Hatcher, B., Nuner, J., \& Paulsel, J. (2012). Kindergarten Readiness and Preschools: Teachers' and Parents’ Beliefs Within and Across Programs. Early Childhood Research \& Practice, 14(2), Retrieved from, http://ecrp.uiuc.edu/v14n2/hatcher.html.

[9]. Kim, J., Murdock, T., \& Choi, D. (2005). Investigation of Parents’ Beliefs about Readiness for Kindergarten: An Examination of National Household Education Survey (NHES: 93). Educational Research Quarterly, 29(2), 3-17.

[10]. Lahaie, C. (2008). School readiness of children immigrants: Does parental involvement play a role? Social Science Quarterly, 89(3), 684-705. McBryde, C., Ziviani, J., \& Cuskelly, M. (2004). 
School readiness and factors that influence decision making. Occupational Therapy International, 11(4), 193-208.

[11]. McClelland, M. M., Cameron, C. E., Connor, C. M., Farris, C. L., Jewkes, A. M., \& Morrison, F. J. (2007). Links between behavioral regulation and preschoolers' literacy, vocabulary, and math skills. Developmental Psychology, 43(4), 947.

[12]. Wildenger, L. K., McIntyre, L. L., Fiese, B. H., \& Eckert, T. L. (2008). Children’s daily routines during kindergarten transition. Early Childhood Education Journal, 36(1), 69-74. 